\title{
Correspondence
}

\section{Social Interventions in the Families of Schizophrenics DEAR SIR,}

The paper by Leff et al (Journal, June 1985, 146, $594-600$ ) is highly unsatisfactory. The number of patients is surely far too small for there to be any validity in the study, yet the conclusions seem to be widely quoted in the psychiatric literature. The design of the experiment was also poor. The patients had no standard drug treatments. Some had injections and others had tablets. The chemical state of those on depot injections varies throughout the period between injections, whereas for tablet takers the condition of the patient does not vacillate so much. The patient may be knocked out for a few days after his injection and towards the end of the period he may become less well due to shortage of medication. Skill in medicating patients would seem to be the first essential in preventing relapses of all schizophrenics. Often medication is not skilfully given and relapses result.

Another drawback to the study is that only one in each group was suffering from paranoid schizophrenia and the rest from nuclear schizophrenia. There are two points here. The families in which there is a paranoid patient would be likely to have suffered in a different way from those with a member suffering from nuclear schizophrenia. I would expect families with a paranoid schizophrenic member to be more emotionally upset when reporting on the behaviour of their ill one. They would be likely to show more high EE. Secondly, it is possible that there were others in some of the families who are genetically a bit high and without the help of medication they would not be able to change themselves. I heard one distraught mother say at a recent meeting "I am a high EE mother". Poor woman, I wonder if undue pressure was being put on her to change.

I think that the worst part of the study is perhaps the figures. 2/10 relapsed in the experimental group and $7 / 9$ in the control $-20 \%: 78 \%$, which the authors say is a highly significant difference. However, 3 of the 7 in the control group who relapsed were suicide attempts. They lived. Two of the experimental group actually committed suicide. They did not relapse, but they died. Their cases were thus far worse than the hospitalised attempts at suicide. If the two suicides are added to the two relapses in the experimental group, the differences between the two groups were not significantly different. This would seem to make the study of no worth, especially remembering the small numbers of people involved.

The authors also quite openly state that the high suicide rate (17\%) amongst the control group might be attributed to their interventions. If they had been trying to help the young girl suicide to loosen the attachment to her mother it is quite possible that they did hasten her demise. Her mother was most probably the girl's main support and she needed her far more than she needed intervening psychiatrists.

Although the patients were randomly selected the much higher average age of the experimental group to the control $(41: 30)$ and the higher age of onset in the experimental group compared to the control (36:26) would be expected to affect the results. When the six experimental cases are cited it would appear that most of them were reasonably stabilised on drugs so that they were able to engage in interesting activities. The fact that they were mostly older was possibly related to the average late onset of their illness, which had enabled them to live pretty normal lives before onset. We are not given similar case histories for the controls.

Lastly, the very fact that the researchers did not repeat the EE assessment at the end of the 2 year study meant that they failed to do what they set out to do. They do not know if their interventions could in any way have been said to reduce high EE to low EE. The second suicide lived alone, so he had almost nil face to face contact and neither was he living with a high EE or a low EE relative. Face to face contact was reduced in the others due to their jobs etc. I doubt very much if reduced contact in these families played any part in the prevention of relapse.

GWYNNETH HEMMINGS

The Schizophrenia Association of Great Britain

International Schizophrenia Centre

Bryn Hyfryd, The Crescent

Bangor, Gwynedd LL57 $2 A G$

\section{Dr Lefi and Colleagues Reply}

DEAR SIR,

The methodological issues raised by Mrs Hemmings are either accommodated by the randomisation procedure we used to assign families to experimental 